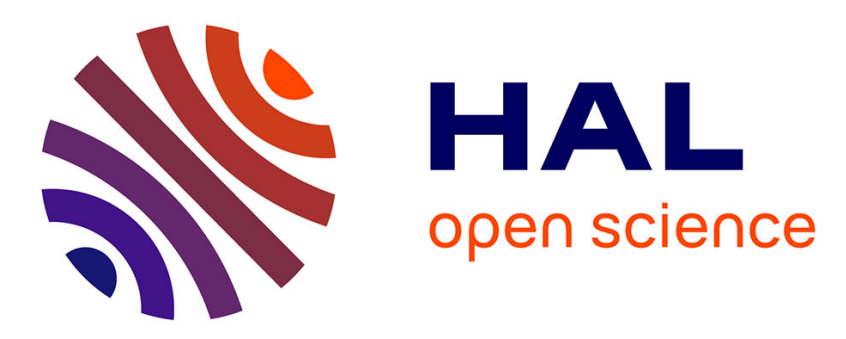

\title{
Chains of freedom: Constraints and creativity in the macro-verb strategies of Mwotlap
}

\author{
Alexandre François
}

\section{To cite this version:}

Alexandre François. Chains of freedom: Constraints and creativity in the macro-verb strategies of Mwotlap. I. Bril et F. Ozanne-Rivierre (eds). Complex predicates in Oceanic languages: Studies in the dynamics of binding and boundness, Berlin: Mouton de Gruyter, pp.107-143, 2004, Empirical Approaches to Language Typology. halshs-00135833

\section{HAL Id: halshs-00135833 \\ https://shs.hal.science/halshs-00135833}

Submitted on 9 Mar 2007

HAL is a multi-disciplinary open access archive for the deposit and dissemination of scientific research documents, whether they are published or not. The documents may come from teaching and research institutions in France or abroad, or from public or private research centers.
L'archive ouverte pluridisciplinaire HAL, est destinée au dépôt et à la diffusion de documents scientifiques de niveau recherche, publiés ou non, émanant des établissements d'enseignement et de recherche français ou étrangers, des laboratoires publics ou privés. 
François, Alexandre. 2004. Chains of freedom: Constraints and creativity in the macro-verb strategies of Mwotlap. In I. Bril et F. Ozanne-Rivierre (eds), Complex predicates in Oceanic languages: Studies in the dynamics of binding and boundness. Empirical Approaches to Language Typology.

Berlin: Mouton de Gruyter. Pp. 107-143.

\title{
Chains of freedom : Constraints and creativity in the macro-verb strategies of Mwotlap
}

\author{
Alexandre François
}

\begin{abstract}
In Mwotlap (north Vanuatu), most verb phrases consist of two or more verb roots chained together $\left\langle\mathrm{V}_{1}-\mathrm{V}_{2} \ldots\right\rangle$, acting like a single verb. Although a clear case of verb serialization, such phrases reveal a strong asymmetry between their free verb head $\left(\mathrm{V}_{1}\right)$, and what appears to be little more than a post-head modifier $\left(\mathrm{V}_{2}\right)$. Because the resulting "macro-verb" can only refer to a single action, its internal structure has to obey strict rules; this paper analyses the way the valencies of both component verbs are capable of consistently merging into that of the whole macroverb, avoiding such things as conflicts between competing objects. Constraining though they may be, these syntactic rules turn out to be a powerful tool serving the speaker's creativity: indeed, this paradoxical "chained freedom" brings about spectacular paths of evolution in the history of Mwotlap macro-verb strategies.
\end{abstract}

\section{Introduction}

Quite diverse kinds of structures have been placed under the term "verb serialization", which might well deserve different analyses. From the formal point of view, a contrast must be made between what has been acknowledged (Foley \& Olson 1985) as "Nuclear-layer serialization" - of the type I hit-die-d your brother - and "Core-layer serialization" - of the type I hit your brother he died. And even after such formal precautions, it might well be also that within a single type, two different languages use similar structures to encode different semantic values - in such a way that it may not be prudent to generalize to all serializing languages the observations made for one of them. For instance, supposing nuclear-layer serializa- 
tion in one language should be proved to refer to single events, it remains possible that the same syntactic device be used, in another language, to refer to several, contiguous events.

Mwotlap is an Oceanic language spoken by approximately 1,800 speakers in northern Vanuatu, Banks Is. (François 2001, 2003). More precisely, it belongs to the genetic subgroup which was labelled 'North-Central Vanuatu' [NCV] by Ross Clark (1985). Most of the NCV languages which have been already described have shown at least one, and sometimes two kinds of serial verb constructions: Paamese (Crowley 1987), Lewo (Early 1993), Namakir (Sperlich 1993), Ambae (Hyslop 2001) all combine nuclear-layer and core-layer serialization patterns; Araki, a language spoken in south Santo by a handful of speakers (François 2002), also has both patterns, but shows a very strong tendency for core-layer SVC. Finally, moving further northwards shows the latter structure to be less preferred than nuclear-layer SVC, in such a way that Mwotlap has virtually no example of core-layer svc [see fn.6]. The latter facts are summarized in the following chart:

Figure 1. Different distribution of serial-verb constructions across some NorthCentral Vanuatu languages

\begin{tabular}{|c|c|c|}
\hline $\begin{array}{l}\text { some NCV } \\
\text { languages }\end{array}$ & $\begin{array}{l}\text { Core-layer SVC } \\
\text { e.g. I hit him he died }\end{array}$ & $\begin{array}{l}\text { Nuclear-layer SVC } \\
\text { e.g. I hit-die-d him }\end{array}$ \\
\hline Paama, Lewo & + & + \\
\hline Araki & + & $(+)$ \\
\hline Mwotlap & - & + \\
\hline
\end{tabular}

The present paper will thus analyse exclusively Nuclear-layer serialization patterns in Mwotlap. In this language, it is very common about twenty per cent of the clauses in spontaneous speech - that a single verb phrase contains not only one verb lexeme, but two or three, and up to four verb radicals, chained together within a single syntactic phrase:

$T \bar{o} \quad k \bar{e}\langle n i-\boldsymbol{h} \overline{\boldsymbol{o}} \quad \overline{\mathbf{m}} \overline{\boldsymbol{l}} \quad$ lok $\rangle \quad h \bar{o} w$.
then 3sG AO-paddle
'Soturn again down
'So paddled his way back to the west.'

After placing these structures in their syntactic context, we will analyse more specifically the way they handle such issues as valency and argument structure. This should not only allow for a better insight into the formal mechanisms of serialization, but also help formulate hypotheses on the semantic and pragmatic functions fulfilled by this strategy. 


\section{The internal syntax of VPs and Nuclear-layer serialization}

It may be useful to present the basic syntax of Mwotlap clauses, so that the reader can appreciate serializing strategies in their proper context.

\subsection{The Verb phrase}

Mwotlap obeys a strict order of constituents $\mathrm{SVO}^{1}$. It is unusual within the North Vanuatu subgroup, in that neither the subject nor the object is crossreferenced on the verb form: both arguments are represented by a noun phrase or a free pronoun (sometimes a zero anaphora), with their function only indicated by their position in the clause. Mwotlap has lost the transitivizing morphology of its ancestors (e.g. POc suffix $*_{-i}$ ):
(2) a. No m-et nēk.
b. Nèk m-et no.
1SG PFT-see 2SG
2sg PFT-see 1SG
'I saw you.'
'You saw me.'

As far as the verb is concerned, it is obligatorily marked as finite by means of a Tense-Aspect-Mood marker. These TAM markers, of which Mwotlap has no less than twenty-five (François 2003), take the form either of a prefix, a pre-clitic, or a post-clitic. A few of these markers are discontinuous, being a combination of a prefix and a post-clitic: e.g. et-... te 'realis negative', te-... vēh 'potential'; they can embrace several elements, which together form the VP. These 'bracketing' morphemes turn out to have a crucial role in the syntactic analysis, since they provide an efficient test for the delimitation of VPs in Mwotlap. For example, they make it easy to observe that Mwotlap VPs do not include the object:

(3) a. Kēy $\langle\boldsymbol{e t}$-galeg te $\rangle \quad n-\bar{e} \bar{m}$.

3PL $\mathrm{NEG}_{1}$-make $\mathrm{NEG}_{2}$ ART-house

'They don't build houses.'

b. Kēy $\langle$ ta-galeg vēeh $\rangle \quad n-\bar{e} \bar{m}$.

3PL $\mathrm{POT}_{1}$-make $\mathrm{POT}_{2}$ ART-house

'They can build houses.' 


\section{Alexandre François}

\subsection{Adjuncts: both a category and a function}

Thanks to the same discontinuous morphemes, it is possible to characterize lexemes or phrases in Mwotlap, whether they can surface inside or outside the VP. Whereas direct objects, as well as oblique complements, are excluded from the VP, several lexemes systematically appear within this verb phrase, immediately following the verb head:

(4) Kōmyō 〈ta-tatal tiwag lok se vēh〉 talōw le-mtap. 2DU $\quad \mathrm{POT}_{1}$-walk together back again $\mathrm{POT}_{2}$ tomorrow in-morning 'You will be able to have a walk together once again tomorrow morning.'

Although all words in bold correspond, in English translation, to a single category called 'adverbs', it is obvious that they must be clearly distinguished for a language like Mwotlap: distributionally speaking, a difference must be made between those words which only fit VP-internal positions (e.g. tiwag 'together'), and those which cannot enter the VP, and take the slot of oblique complements (e.g. talow 'tomorrow'). We reserve the term 'Adverb' for this second category, while the VP-internal words correspond to a specific function which we label 'Adjunct'. Semantically speaking, adjuncts have the function of a head-modifier, in very much the same way as adjectives modify the nominal head of an NP.

Sentence (4) suggests that while a single verb phrase can perfectly include several adjuncts, only one verbal head is allowed at a time. To sum up, the structure of a verbal clause in Mwotlap obeys the following pattern:

Subject $\left\langle_{\text {там }}\right.$ verbal head + Adjuncts тAм $_{\text {Ta }}$ Object + Complements

A crucial remark to be made, is that the syntactic slot of adjunct is not reserved to a few lexemes specialized in this function ("pure adjuncts"), like tiwag or lok in (4). In fact, several versatile lexemes, as well as whole categories, do fit the same verb-modifying position. For example, virtually all lexical adjectives, besides their function as noun-modifiers, can also modify semantically a verbal head, taking the slot of an adjunct:

(5) a. na-lqōvēn qaqa

ART-woman stupid

'a foolish woman'

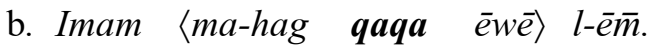

Dad PFT-sit stupid just in-house

'Dad is staying idly at home.' 
(6) a. nu-qul lawlaw

ART-lamp bright

'a red lamp / a shining lamp'

b. $\langle$ Tog etet lawlaw $\rangle \bar{e}$ !

PROH look:DUP bright 3sG

'Stop watching her with those bright [i.e. greedy] eyes!'

Although this is less frequent, some nouns appear in the same position of adjunct:

(7) Kē 〈ma-hag tuvusīel $\rangle$ hōw.

3SG PFT-sit high.chief down

'He is sitting cross-legged.' [lit. He is sitting high-chief]

(8) Tigsas kē $\langle e t-w o t \quad v u \quad t e\rangle, k \bar{e}\langle m o-w o t e t\rangle$.

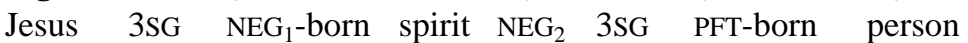

'Jesus Christ was not born a spirit, he was born a man.'

Through this use in the adjunct position, the set of lexical adjectives and the set of nouns both provide a stock of possible verb-modifiers, allowing new combinations to be built in order to express semantically complex processes.

\subsection{Nuclear-layer serialization and the status of $\mathrm{V}_{2}$}

It is now possible to present the serializing sentence (1) above, repeated below:

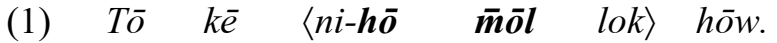

then 3SG AO-paddle return again down

'So he paddled his way back to the west.'

This sentence may be seen as a typical instance of nuclear-layer serialization: a single verb phrase includes more than one verb radical here two. Tense-aspect-mood markers only appear once, affecting the complex verb phrase as a whole: prefixes come before the first verb, and post-clitics appear after the last verb or the last adjunct. Nothing can intervene between two serialized verbs, especially no object phrase; the object of the first verb $V_{1}$, if any, is either left implicit, or becomes the object of the whole verb phrase: 


\section{Alexandre François}
(9) a. Tali 〈mi-tit
tō Kevin.
T. PRET $_{1}$-punch PRET 2 K.
'Tali punched Kevin.'
b. Tali $\langle$ mi-tit teñteñ tō $\rangle$ Kevin.
T. PRET 1 -punch cry:DUP PRET $_{2}$ K.
'Tali made Kevin cry by punching him.'

The issue of argument structure and valency will be addressed in Section 3. At this point of the discussion, it may be relevant to ask the following question: in serializing structures like (1) and (9), should we consider that the verb phrase contains two verbal heads? or is the first verb still the unique head, whereas the second one would be described as its adjunct?

The right answer to this question seems to be the second one: in a sequence $\left\langle V_{1}+V_{2}\right\rangle$, the serialized verb $V_{2}$, far from being a second head, is nothing more than an adjunct to the preceding verb $V_{1}$. The first reason for this claim is the high parallelism between serialized verbs and adjuncts: they take the same syntactic slot in the verb phrase, and both have the semantic function of modifying the first verb $\mathrm{V}_{1}$. Whatever its internal complexity, the whole VP $\left(\mathrm{V}_{1}+\right.$ adjunct, or $\left.\mathrm{V}_{1}+\mathrm{V}_{2}\right)$ can be understood as a mere development of $\mathrm{V}_{1}$, with the same basic lexical meaning: for example,

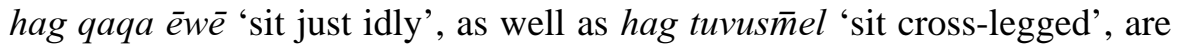
nothing more than two possible ways to hag 'sit'; etet lawlaw 'watch greedily' refers to a way of watching; $h \bar{o} \bar{m} \bar{o} l$ 'paddle back' is an instance of paddling; and tit teñteñ 'knock to make cry' is a sub-type of tit 'knock', but not a sub-type of $t e \bar{n}$ 'cry'.

The latter remark can be reworded in more narrowly syntactic terms: the verbal head of a VP necessarily takes the same subject as the whole phrase of which it is the head. Thus Tali in (1) is both the subject of tit 'knock' and of the whole VP mi-tit teñte $\bar{n}$ tō 'knocked in such a way to make cry'. On the contrary, the following verbs in an SVC are not subject to the same syntactic constraint regarding their subject: although both verbs in (1) do have the same subject, this is not the case in (9), where the only suitable head is the first verb $\mathrm{V}_{1}$.

Among other arguments which will not be detailed here, the asymmetry which we claim exists between $V_{1}$ and $V_{2}$ is confirmed by a difference in their lexical inventory. Whereas all verb lexemes of Mwotlap can be the head $\left(\mathrm{V}_{1}\right)$ of a serializing $\mathrm{VP}$, the subsequent position $\left(\mathrm{V}_{2}\right)$ is restricted to a much smaller set of verbs, probably a few dozen; for example, such common verbs as van 'go', lep 'take', et 'see' never appear in the position of 
$\mathrm{V}_{2}$. And even the verbs which can fit both positions $\left(\mathrm{V}_{1}\right.$ or $\left.\mathrm{V}_{2}\right)$ sometimes show traces of asymmetry in their forms: e.g. the verb 'know' has the form $\bar{e}$ glal when found in $\mathrm{V}_{1}$, but veglal when in $\mathrm{V}_{2}$; the duplicated form of the verb sok 'search' is soksok when in $\mathrm{V}_{1}$, but sosok when in $\mathrm{V}_{2}$, and similarly têy 'hold' duplicates regularly as têytey when it is the head of the VP, but as têtêy when it is used as a head-modifier. All these remarks tend to demonstrate that what looks, at first sight, like a simple chain of verbs $\left[\mathrm{V}_{1^{-}}-\mathrm{V}_{2^{-}}\right.$ $\left.\mathrm{V}_{3} \ldots\right]$ placed on the same level, involves in fact an asymmetrical relationship, that of a head followed by its modifiers.

Consequently, the best way to analyse serial verbs in Mwotlap follows the model Head + Adjunct. $^{3}$ This pattern fits well in the category identified by Durie (1997) as asymmetrical serial constructions, whereby a single verbal head $\left(\mathrm{V}_{1}\right)$ is modified by a limited set of verbal modifiers $\left(\mathrm{V}_{2}\right)$.

\subsection{One or several actions?}

It is perfectly possible that this analysis of Mwotlap does not match the structures of other serializing languages, in which SVCs would basically allow for a string of successive actions performed by the same subject. For example, the following sentence in the Papuan language Barai ${ }^{4}$ could well lead to the opposite conclusion, i.e. one VP having several heads:

\section{BAR $E$ ije fu a-nafa-fu-o kan-ia buvua $i$. man the 3SG child-PL-3SG-POSs kill-3PL cut.up eat 'The man killed, cut up (and) ate his children.'}

Now, the reader must realize that such a string of actions ${ }^{5}$ would never be coded by a serial structure in Mwotlap. Contrary to what is suggested by the general label 'serial verbs', this language will combine verbs in a single VP to refer to a single action, and hardly ever more. When Mwotlap needs to describe a series of actions, it does not use serialization, but coordination, by means of such conjunctions as $b a$ 'and' or $t \bar{o}$ 'so, then' - in a way very similar to European languages.

The following example should help fix this important point. It is the narration of a series of successive actions undertaken by an individual (a healer called Boyboy) within a short period of time. Although this is typically the kind of context in which many serializing languages would make use of serial verbs, it is remarkable that Mwotlap codes all these actions by means of distinct clauses, separated by prosodic pauses ${ }^{6}$ and/or coordinators (underlined): all these devices are typical of non-serializing languages. 
(10)

Bōybōy me-yem, ma-hap, me-hēw tēy wonwon; B. PFT-climb PFT-pick PFT-descend hold intact:DUP 'B. climbed (up the coconut-tree), picked (some coconuts), brought them down intact;

$\underline{t o} \quad k \bar{e} n i-e y, \quad \underline{t o} \quad k \bar{e} \quad n i-v a n$ têy me l-ēm; then 3SG AO-husk then 3SG AO-go hold hither in-house then he husked them, then he brought them home;

$\begin{array}{llllllll}k \bar{e} & n i-t o t & n \bar{e}-t \bar{e} n g e & n a n, & k \bar{e} & n i-v a n & \text { teyy } & m e, \\ 3 \mathrm{SG} & \text { AO-chop } & \text { ART-leaf } & \text { ANA } & \text { 3SG } & \text { AO-go } & \text { hold } & \text { hither }\end{array}$

he cut the relevant (medicinal) leaves, he brought them here;

tō ni-bōl madamdaw nō-gōygōyi qētēnge nan, ... then AO-hammer soft ART-roots plant ANA then he crushed their roots soft, ...

$\underline{t o}$ lep me tō nok in $\underline{t \bar{o}}$ nok we then take hither then 1SG AO:drink then 1SG AO:good $\underline{\text { then }}$ gave it to me, then I drank it, then I got better,

$\underline{t o} \quad n i-b a h$.

then AO-finish

and this is it.'

Nevertheless, serialization patterns are not totally absent from the last citation; they appear in bold. In each case, what we observe is a single VP, inflected with a single TAM prefix ( $m \bar{e}-, n i-)$, and including more than one verb radical - which corresponds well to the formal definition of 'serialization'. But from the semantic point of view, we claim that each of these serializing VPs points to a single, minimal action, with no possibility to split it into distinct phases in time. Here they are repeated:

(11) Bōybōy $\langle m \bar{e}-\boldsymbol{h} \overline{\boldsymbol{e}} \boldsymbol{t}$ tēy wonwon $\rangle$.

B. $\quad$ PFT-descend hold intact:DUP

'Boyboy brought them down without-breaking-them.'

(12) ke $\langle n i-v a n$ têy $\rangle$ me l-ēm.

3sG AO-go hold hither in-house

'He brought them home.'

(13) tō 〈ni-bōl madamdaw $\rangle$ no-gōygōyi qētēnge nan then AO-hammer soft ART-roots plant ANA 'then he softened the roots of the plant by hammering them'

Without going into too much detail here, it is instructive to notice that the internal structure of serializing VPs in Mwotlap confirms our claim that 
they cannot be interpreted as a series of actions. Indeed, it is common in most serializing languages, to translate such a verb as Eng. 'bring' by a string of two actions $\mathrm{V}_{1}=$ 'take' $+\mathrm{V}_{2}=$ 'come'; e.g. pidgin Bislama follows iconically the order of the two phases:

$\begin{array}{lllll}\text { BSL Hem } i \quad \text { karem kokonas } & i \text { kam. } \\ \text { 3SG PRD carry coconut PRD come } \\ \text { 'He brought a coconut.' }\end{array}$

In these languages, it is still possible to consider this string of two verbs as reflecting two successive (phases of) actions. On the contrary, Mwotlap codes the same idea using a non-iconic order of terms $\left[\mathrm{V}_{1}=\right.$ verb of movement $+\mathrm{V}_{2}=$ 'hold'], in such a way that the " $n$ verbs, $n$ actions" interpretation becomes impossible. The only reading possible for sentences (11) and (12) corresponds not to successive actions, but to simultaneous facets of a single action: Boyboy descends (from the tree) holding (the coconuts) and keeping them in one piece.

\subsection{Summary: An optical illusion}

We can now summarize the results of these first observations about Mwotlap. In this language, a single verb phrase may include more than one verbal lexeme at a time, with no other element intervening. The surface pattern $\left\langle\mathrm{V}_{1}+\mathrm{V}_{2}+\mathrm{V}_{3} \ldots\right\rangle_{\mathrm{VP}}$ recalls similar strings of verbs in certain languages - like Tariana (Aikhenvald 1999) - and suggests the term of '(nuclearlayer) verb serialization' for Mwotlap.

However, a deeper analysis shows that the term 'serial verb' may well be an optical illusion. First, there is a formal and semantic asymmetry between $V_{1}$, the unique head of the verb phrase, and the following verbs, whose basic role is to modify this head. In this sense, serialized verbs enter a syntactic slot we have called 'adjunct'; far from being exclusive to verbs, the position of adjunct is also open to adjectives and nouns, plus many lexemes ("pure adjuncts") exclusive to this function. From the semantic point of view, a serial verb string in Mwotlap cannot refer to several distinct actions - in which case, coordination is used - but to a single action, undertaken by one subject at a given point in time. The internal complexity of these SVCs allows coding this single action under several of its facets. Focusing on the issue of valency and argument structure, the second section of this paper will examine the way this complexity is handled by the socalled ‘serializing' strategy. 


\section{Serial verbs and transitivity issues}

After this first exploration of Mwotlap SVCs, we would like to focus our attention on the relations existing between the argument structure of a serialized VP and that of its components. Indeed, we have already seen that a multi-verb VP behaves externally like any simple verb, having one subject on its left, and no more than one object on its right. Knowing that Mwotlap does not allow for double-object structures (Eng. I gave him a pen), nor is it possible to insert any object NP between two serialized verbs, syntactic conflicts may arise in the combination of two transitive verbs (see [o] below).

In reality, cases of valency conflict seldom occur in Mwotlap svCs. Most of the time, what is observed is a regular capacity to merge the argument structures of two verbs into that of a new, composite 'macro-verb'. The following paragraphs will try and establish a syntactic classification of Mwotlap SVCs, according to the argument structure of their input elements, and of the output verb phrase.

Basically, the main relevant opposition is that between intransitive and transitive verbs: for instance, we will see in which cases the combination of two intransitive verbs leads to the formation of an intransitive or a transitive VP. But for this analysis, finer criteria will be needed, such as the sameness or difference between, say, the object of $V_{1}$ and the subject of $V_{2}$, etc. As a consequence, each type in the following classification will be presented with a simple formula, using small letters $(x, y, z)$ for arguments, and an SVO convention; e.g. $\mathrm{x}-\mathrm{V}_{1}$ means ' $\mathrm{V}_{1}$ is an intransitive verb having a subject $x$ '; $\mathrm{x}-\mathrm{V}_{2}-\mathrm{y}$ means ' $\mathrm{V}_{2}$ is a transitive verb having a subject $x$ and an object $y^{\prime}$.

A short note is necessary here about the category "adjective". In Mwotlap as in many Austronesian languages, adjectives follow the same syntactic patterns as intransitive verbs, in most contexts: both categories are directly predicative, they combine with the same aspect-mood markers, and so on; the only position where they can be distributionally contrasted is inside the noun phrase, since only an adjective can modify a noun directly. Because our study is concerned with serial constructions in predicative phrases, where adjectives and verbs are merged, it will here be legitimate to regard adjectives as a sub-class of intransitive verbs, following the pattern $\mathrm{X}-\mathrm{V}_{1} \cdot{ }^{7}$ 
3.1. Both verbs are intransitive

[a]

$$
x-\mathrm{V}_{1}+x-\mathrm{V}_{2} \rightarrow x-[\mathrm{VP}]
$$

Both verbs can be intransitive. If their individual subject is semantically the same, then the output is normally an intransitive macro-verb. Semantically, the subject can be said to perform both 'actions' - or, to be more precise, both facets of the same action - at the same time.

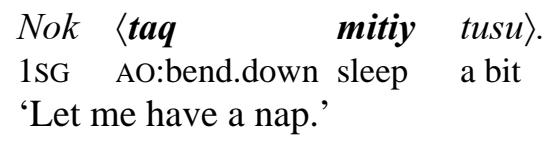

(15) Gēn 〈yow tig $\rangle$ hōw lē-bēe! $1 \mathrm{IN}: \mathrm{PL}$ AO:jump stand down in-water 'Let's jump into the river!'

(16) Inti $\langle$ ma-kal qeleñ $\rangle$. son:2SG PFT-crawl disappear 'Your baby's crawled away.'

As was mentioned before, nothing prevents us from adding to the present list those cases in which the adjunct $V_{2}$ is an adjective (or "adjectival verb”), with the same semantic subject as $\mathrm{V}_{1}$ :

$$
\begin{aligned}
& K \bar{e} \quad\langle\text { me-teñ magaysēn }\rangle . \\
& \text { 3SG PFT-cry sad } \\
& \text { 'He was crying miserably.' }
\end{aligned}
$$

$$
x-\mathrm{V}_{1}+x-\mathrm{V}_{2} \rightarrow x-[\mathrm{VP}]-x
$$

A rather strange pattern provides an exception to [a] above, since it shows two intransitive verbs with the same subject, resulting in a formally transitive macro-verb. The object of this VP has the same reference as its subject, which corresponds, incidentally, to the coding of reflexive verbs in Mwotlap.

In fact, this pattern [b] occurs only in familiar speech, with basically two verbs in adjunct position: mat 'die' and its slangish counterpart mem 'piss'. The basic idea is that the subject $x$ is performing an (intransitive) action $V_{1}$ in such an intense manner, that it makes him metaphorically die... or, less seriously, urinate. Practically, this structure is used as a jocular intensifier for certain intransitive actions: 


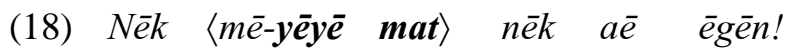
2SG PFT-laugh die 2SG ANA now 'You're laughing yourself to death!'

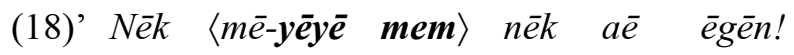
2SG PFT-laugh piss 2SG ANA now (slang) 'This makes you piss with laughter!'

In order to be understood, this isolated pattern [b] should be compared to others, more productive. For instance, it can be interpreted with reference to [e] below - except that in this case $x=y$. Or it may also be compared with the causative structure ([j] below), with which both verbs mat and mem are usually associated, in phrases like $\left\{\mathrm{x} \mathrm{V}_{1}\right.$ mat $\left.\mathrm{y}\right\}$ ' $x$ kills $y$ (through the action $\mathrm{V}_{1}$ )' or $\left\{\mathrm{x} \mathrm{V}_{1}\right.$ mem $\left.\mathrm{y}\right\}$ ' $\mathrm{x}$ makes $y$ piss (through a violent action $V_{1}$, e.g. knock down or scare)'. What is particular in (18)(18)', is that $V_{1}$ is intransitive, and the patient coincides with the actor ${ }^{8}$.

[c]

$$
x-\mathrm{V}_{1}+=\mathrm{V}_{2} \rightarrow x \text {-[VP] }
$$

It sometimes happens that the logical subject of $\mathrm{V}_{2}$ is not just $x$ (the subject of $\mathrm{V}_{1}$ ), but rather corresponds to the predicate structure $x-\mathrm{V}_{1}$ as a whole. The verb $V_{2}$ comments on the manner in which the action $(x-) V_{1}$ is carried out. ${ }^{9}$ This is often the case when the serialized element is an adjective, which may then be said to work as an "adverb":

Na-day nono-n $\langle$ me-plag lililwo $\rangle$.
ART-blood of-3sG PFT-run big:DUP
'His blood flowed abundantly.'

(20) No-qo e kē $\langle$ ma-mat hiywe $\rangle$. art-pig ANA 3sg PFT-die be.true

'The pig was well and truly dead.'

In example (20), it is clear that the subject of $V_{2}$ 'be true' is not the pig itself, but 'the dying of the pig': the logical structure of these sentences is thus $\left\{\mathrm{V}_{2}\left(\mathrm{~V}_{1}(x)\right)\right\}$, involving a second-order predicate. See also [h].

$$
x-\mathrm{V}_{1}+\varnothing-\mathrm{V}_{2} \rightarrow x-[\mathrm{VP}]
$$

Sometimes, an intransitive $\mathrm{V}_{1}$ is combined to an impersonal verb $\mathrm{V}_{2}$, with zero-valency ${ }^{10}$, e.g. $q \bar{o} \bar{n}$ 'be night', myen 'be daylight'. The latter does not affect the valency of the main verb, and adds only the meaning '(do $V_{1}$ ) until it is night [resp. day]'. 
(21) Tita 〈ni-hag qō̄n $\rangle$ l-ēm.

Mum AO-sit be night in-house

'Mum will stay at home all day long.'

(22) Kimi $\langle$ ma-lak meyen tō $\rangle$ ?

2PL PRET $_{1}$-dance be day PRET $_{2}$

'Did you dance all night long?'

[e] $x-\mathrm{V}_{1}+y-\mathrm{V}_{2} \rightarrow x-[\mathrm{VP}]-y$

Two intransitive verbs may merge into a transitive macro-verb: this happens when the semantic subject of $V_{2}$ is different from that of $V_{1}$. In this pattern, the general meaning is " $x$ performs/undergoes an intransitive action $\mathrm{V}_{1}$, which results in another element $y$ undergoing in turn a transformation $\left(\mathrm{V}_{2}\right)$ "; the syntactic output of this combination is a transitive macro-verb $\left\langle\mathrm{V}_{1}-\mathrm{V}_{2}\right\rangle$ with a causative meaning. Notice that the present pattern normally does not concern animate actors, but rather natural forces: with an animate subject, the feature [control] would normally result in the choice of a transitive $\mathrm{V}_{1}$.

(23) Na-lo 〈ni-hey simsim $\rangle$ n-aes. ART-sun AO-shine melt:DUP ART-ice

'The sun melts the ice (by shining).'

(24) Ne-lē̄ 〈mi-yip hal-yak $\rangle$ na-kat.

ART-wind PFT-blow fly-away ART-cards

'The wind blew the cards away.'

(25) Ni-yiy 〈mi-yiy sisisgoy $\rangle$ na-mtig.

ART-quake PFT-quake fall:DUP ART-coconut

'The earthquake made the coconut trees fall down.'

Even when it is animate, the subject is generally not agentive - but note ex. (27):

(26) Nēk 〈mi-tig mēelèmlēg $\rangle$ na-lo den kemem.

2SG PFT-stand black ART-sun from 1EX:PL

'Standing as you are, you're hiding the sun from us.'

[lit. You're standing dark the sun from us.]

(27) 〈Gengen maymay $\rangle$ na-taybēe!

AO:eat:DUP strong ART-body:2SG

'Eat well, to strengthen your body.' [lit. Eat strong your body.] 


\section{2}

\section{Alexandre François}

To our knowledge, pattern [e] was never witnessed in any other serializing language which has been described to date. It must be distinguished from the so-called 'switch-subject serialization' ([j]), since the first verb is intransitive: we would call it "low agency causative serialization". Most remarkably, this structure contradicts the claim usually made about serialization, that "serial verbs share at least one (...) argument" (Durie 1997: 291): Mwotlap proves that two predicates, having no argument in common, can perfectly merge into a single serial verb construction. ${ }^{11}$ The structure, however, is rare: our corpus shows little more than the few examples cited here.

Any combination of the above formulas, involving more than two verbs, leads to the expected result. We will give here only one example, which combines [c] and [d] above: the combination of an intransitive verb + an adjunct commenting on this first action + an impersonal adjunct, results in an intransitive macro-verb.

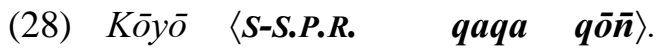 \\ 3DU AO:roam:DUP stupid be night \\ 'They spend the whole day aimlessly wandering. ${ }^{12}$}

The formula corresponding to this example would be:

$$
x-\mathrm{V}_{1}+=\mathrm{V}_{2}+\varnothing-\mathrm{V}_{3} \rightarrow x-[\mathrm{VP}]
$$

Such combinations are very common in everyday speech, and there even seems to be a preference for this kind of multi-verb serialization in colloquial discourse and slang.

\subsection{Only one verb is transitive}

When only one verb is transitive, then the result of the combination is invariably a transitive VP.

$$
x-\mathrm{V}_{1}-y+x-\mathrm{V}_{2} \rightarrow x-[\mathrm{VP}]-y
$$

Despite its simplicity, this pattern seldom occurs in Mwotlap: usually, the combination of a transitive head with an intransitive adjunct is interpreted as a 'switch-subject serialization' ([j] below), i.e. a causative structure in 
which the subject of $\mathrm{V}_{2}$ is understood to be $y$, not $x$. However, the following example is compatible with the interpretation [g]:

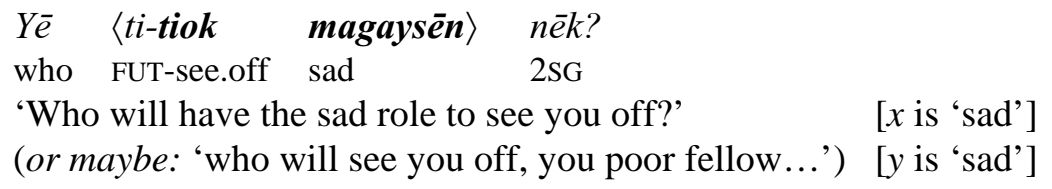

[h]

$$
x-\mathrm{V}_{1}-y+=\mathrm{V}_{2} \rightarrow x-[\mathrm{VP}]-y
$$

An intransitive verb, or often an adjective, can describe the manner of a transitive action $\mathrm{V}_{1}$. In comparison with other patterns, what appears here is that the logical argument of predicate $\mathrm{V}_{2}$ is neither $x$ nor $y$, but the whole event $\left\langle x-\mathrm{V}_{1}-y\right\rangle$ : this is another case of so-called 'ambient serialization' (see [c]).

(30) Na-bago 〈mi-ñit maymay $k \bar{e}$.

ART-shark PFT-bite hard 3SG

'The shark bit him viciously.'

(31) Kèy 〈sok walēg $\rangle$ kèy le-pnō.

3PL AO:seek round 3PL in-island

'They looked for them around the island.'

(32) Ige taman kēy 〈tit-vasem soloteg vēste〉 na-halgoy en.

$\mathrm{PL}$ man 3PL $\mathrm{POT}_{1}: \mathrm{NEG}_{1}$-reveal random $\mathrm{POT}_{2}: \mathrm{NEG}_{2}$ ART-secret ANA

'Men must not carelessly reveal the secrets (of initiation).'

For example, in (30), what is 'hard' is neither the shark itself nor its victim, but the whole state of affairs '[the way] the shark bit him'. This corresponds exactly to the logical description of adverbial modifiers in a language like English, which take a second-order predicate as their logical subject (Dik 1989: 193).

[i]

$$
x-\mathrm{V}_{1}-y+\varnothing-\mathrm{V}_{2} \rightarrow x-[\mathrm{VP}]-y
$$

In a way parallel to [d] above, it is perfectly possible to combine a transitive verb with an impersonal ("weather") verb, leading to a transitive verb phrase. $\mathrm{V}_{2}$ acts as an adverb -more precisely an "intransitive adjunct"without affecting the valency of $\mathrm{V}_{1}$ : 


\section{Alexandre François}

(33) Kem 〈soksok meyen tō $\rangle$ nekk. 1EX:PL seek:DUP be day PRÉT 2SG 'We've been looking for you all night.'

$[\mathrm{j}]$

$$
x-\mathrm{V}_{1}-y+y-\mathrm{V}_{2} \rightarrow x-[\mathrm{VP}]-y
$$

One of the most frequent serializing patterns in Mwotlap has a causative meaning: an actor $x$ acts $\left(\mathrm{V}_{1}\right)$ upon a patient $y$ in such a way that $y$ undergoes the intransitive process $V_{2}$. This structure was called 'switch-subject serial verbs' or 'serial causative verbs' by Crowley (1987:39). Sentences (9) and (29) above already illustrated this case.

(34) No 〈ma-kay metewot〉 na-tm̄an vōyō.

1SG PFT-shoot injured ART-man two

'I wounded two men (by shooting at them).'

(35) Kōyō $\langle m \bar{o}-\boldsymbol{b} \bar{o} w \quad l i w o\rangle k \bar{e}$.

3DU PFT-bring.up big 3SG

'They brought him up (till he was big).'

(36) Kè 〈ni-vatne lolmeyen $\rangle$ gēn.

3SG AO-teach wise 1IN:PL

'He makes us wise (through his teaching).'

The usual causative structure ${ }^{13}$, which uses $a k$ 'make' $+\mathrm{V}_{2}$, can also be described as a serial verb structure:

$$
\begin{array}{cc}
\langle\boldsymbol{A} \boldsymbol{k} & \boldsymbol{t o g - y o n}\rangle \\
\text { AO:make } & \text { stay-quiet } \\
\text { 'Make him be quiet!' } &
\end{array}
$$

But it must be noticed that Mwotlap speakers, whenever they want to express such a causative action performed by $x$ upon $y$, will always prefer to use a more specific verb than $a k$ 'make' in the first position. For example, the action of 'softening' will seldom be expressed ak madamdaw 'make soft': despite being correct, such a phrase is felt to be incomplete or childish. The most idiomatic strategy is to use the 'switch-subject serialization', by specifying the action $V_{1}$ which is supposed to result in the patient becoming 'soft': by hammering it, by chewing it, by pulling on it, etc. In a way, this strategy just consists in "replacing" the all-purpose verb $a k$ by a semantically more specific verb, e.g. $b \bar{o} l$ 'hammer', etc. This is the case in (13), and other similar sentences: 
(38) Kè 〈ni-kuy madamdaw $\rangle$ na-ga.

3SG AO-chew soft ART-kava

'He softened the kava by chewing it.'

(39) Lep ne-vet wiyiwyiy, ba 〈wiyiy madamdaw〉.

AO:take ART-stone grind:DUP and AO:grind soft

'You take the grinding stone, and soften (the kava) by grinding it.'

Through these examples, the serializing strategy clearly appears as a way to gather the semes included in several individual verbs, and merge them into a single macro-verb. The resulting VP is an attempt to encode the complexity of a single action by expressing several of its facets. As we have already pointed out, it would be misleading to consider these chains $\mathrm{V}_{1}-\mathrm{V}_{2}$ to reflect two successive events in time (e.g. he hammered the roots, and then they became soft); rather, the two radicals form a narrow bundle, evoking the specific action of softening something by hammering it.

$$
x-\mathrm{V}_{1}-y+z-\mathrm{V}_{2} \rightarrow x-[\mathrm{VP}]-z
$$

A less frequent variant of the causative pattern we have just presented also combines a first transitive verb $\mathrm{V}_{1}$ with an intransitive verb $\mathrm{V}_{2}$; but the subject of $\mathrm{V}_{2}$ is by itself a new element $(z)$, corresponding neither to the subject $(x)$ nor to the object $(y)$ of $V_{1}$. Since there is only one object slot available for two distinct applicants $(y / z)$, we are facing here the first case of syntactic conflict between arguments.

The solution adopted by Mwotlap is normally to drop the object $y$ of $V_{1}$, thus leading to a transitive verb oriented towards $z$, the experiencer of $V_{2}$ : $\{x$-[VP]-z $\}$. Often, $y$ either features as a topic in the same sentence [see also ex. (48) below], or is easily reconstructed from the discourse context:

(40) Tita nonon mi-gil nē-qyō-n, 〈mi-gil wawah $\rangle n a-t a q \bar{m} \bar{e}-n$. mother his PFT-dig ART-grave-3SG PFT-dig clean ART-body3SG

'His mother dug his grave, cleaning (the earth) off his body.' [lit. she dug his grave, dug clean his body] 
(41)

Kè ma-yah nē-sēm nen etō $\langle n i-y a h \quad \bar{o} \boldsymbol{l} \overline{\boldsymbol{o}} \boldsymbol{l}\rangle$

3SG PFT-scrape ART-cowrie that then AO-scrape call:DUP $n \bar{e}-y \bar{e} d \bar{e} p \quad \bar{e} g \bar{e} n$.

ART-Pritchardia now

'And as she was scraping those cowries (to make shell-money), her scraping made the palm leaf screech.' [lit. she scraped screech the leaf]

(42) $K \bar{e} \quad\langle$ ma-vap lolmeyen $\rangle$ nēk.

3SG PFT-say aware 2SG

'She said (it) to let you know.' [lit. she said aware you]

The last sentence can be compared with (36) above: whereas the implicit object of vatne 'teach (s.o.)' was the same as the subject of lolmeyen, we have here a verb $\mathrm{V}_{1}=$ vap 'say (s.th.)', whose object is different from that of the whole macro-verb: it has to be sought in the preceding context.

The combination vap lolmeyen is the usual way to translate the notion 'inform s.o. of s.th.', 'let s.o. know s.th.' This makes it easy to understand why, in a language like Mwotlap having only one object-slot, conflicts may arise as to which of the two semantic objects will be retained as such in the final structure - whether the 'news' itself (underlying object of vap $=y$ ) or the 'person informed' (underlying subject of lolmeyen $=z$ ); (42) shows that the second choice is the right one, the object of $\mathrm{V}_{1}$ being left implicit.

Interestingly, these serializing strategies may be viewed as a powerful way to increase the density of information within the narrow limits of a single VP, hence increasing semantic explicitness - but it could also be seen, conversely, as a laconic shortcut in which much of the information has to be left unmentioned, with only a small selection of semes coming to light. The right conclusion will depend on the point of comparison: as opposed to a single verb V, a combination of two or more will certainly bring about new elements and richer information. But if a complex verb $\left\langle\mathrm{V}_{1}-\mathrm{V}_{2}\right\rangle$ were to be compared with a linkage of two corresponding full clauses with their own arguments, then what would appear would certainly be some kind of semantic loss and blurring. This is precisely the case with (42). 'She said aware you', which contains more than just She made you aware - but less than She said these words to make you aware. With such serial structures, languages seem to be testing the limits between semantic explicitness and syntactic concision. This risk of uninterpretability is certainly the reason why [k] occurs seldom in Mwotlap, while multi-clause strategies are preferred. ${ }^{14}$ 
[1]

$$
x-\mathrm{V}_{1}+x-\mathrm{V}_{2}-y \rightarrow x-[\mathrm{VP}]-y
$$

This new pattern is as important as the causative one [j], but although they both lead to the same surface result, the mechanism is quite different. Often, we have a first intransitive verb, referring to a single-argument action $\left(\mathrm{V}_{1}\right)$; but for its subject $x$, this first action can also be presented as a way to act upon a patient $y$, or as a process $\left(\mathrm{V}_{2}\right)$ involving, in one way or another, a binary relationship between two elements $x$ and $y$. The result of this is always a transitive verb phrase.

$$
\begin{array}{lll}
\text { a. Kömyō } & \langle\text { ta-kaka } & v \bar{e} h\rangle . \\
\text { 2DU } \mathrm{POT}_{1} \text {-chat } & \mathrm{POT}_{2} \\
\text { 'You may discuss.' } & \text { [intr.] }
\end{array}
$$

b. Kōmyō 〈ta-kaka gatay vēh $\rangle$ no. 2DU $\quad \mathrm{POT}_{1}$-chat mention $\mathrm{POT}_{2}$ 1SG

'You may discuss about me.' [discuss mentioning me]

\section{c. Kōmyō 〈ta-kaka tatag vēh〉 na-myōs.}

2DU $\mathrm{POT}_{1}$-chat follow $\mathrm{POT}_{2}$ ART-desire

'You may discuss freely.' [discuss following your desire]

In these sentences, the act of 'chatting' $\left(\mathrm{V}_{1}\right)$ is presented as involving a secondary semantic relationship between the subject $x$ and another contextual element $y$. In each case, the function of the serialized verb $\mathrm{V}_{2}$ is to introduce a relational seme $f(x, y)$ involved in the process. Thanks to the serial strategy, the speaker is able to mingle unary semes (e.g. ' $x$ chats') and binary semes (e.g. ' $x$ mentions $y$ ') in order to construe a satisfying representation of a given situation. To avoid syntactic conflicts between objects, only one such combination can occur in a given clause: therefore, it is not possible to say in Mwotlap You may talk freely about me; the speaker would have to use more than one clause to encode all these relations.

By adding a relational seme ${ }^{15}$ to the main verb, the adjunct serialized here (gatay, tatag) also has the remarkable effect of increasing its valency. This has important, synchronic and diachronic, consequences, which may lead $V_{2}$ to grammaticalize as a transitivizing morpheme - an issue which will be detailed in the last section of this paper (4.3).

The "argument-adding" pattern under discussion is particularly developed when the head verb expresses movement [see ex. (11)-(12)], like van 'go', hèw 'go down', veyykal 'go up', hayveg 'go in', kalo 'go out', hō 'paddle'...: all these motion verbs, and many more, are attested combining with a transitive adjunct $\left(\mathrm{V}_{2}\right)$, in order to gain one extra slot in their argu- 
ment structure - that is, gain an object. The proper meaning of $\mathrm{V}_{2}$ involves a relational seme between $x$ and $y$ :

$$
\begin{aligned}
& \text { No }\langle\text { ma-van têy }\rangle \text { na-gasel mino. } \\
& \text { 1sG PFT-go hold ART-knife my } \\
& \text { 'I took my knife away (with me).' }
\end{aligned}
$$

(45) No 〈ma-van veteg $\rangle$ na-gasel mino. 1SG PFT-go (leave) ART-knife my

'I left my knife behind (when going).'

$$
\begin{array}{llll}
\text { No }\langle\text { ma-van } & \text { goy } & \text { na-gasel } & \text { mino. } \\
\text { 1SG PFT-go } & \text { (over) } & \text { ART-knife } & \text { my } \\
\text { 'I went to fetch my knife.' } &
\end{array}
$$

In each sentence, the agent's movement (van 'go') involves a certain semantic relationship regarding the knife: he has it with him / he leaves it behind him / he is looking for it, etc. Note that only (44) can be said to involve a true serial structure, because têy is still productive as a head verb in modern Mwotlap; as for veteg in (45), it used to be a serialized verb, but is now becoming a pure adjunct (4.3.2) and the adjunct goy in (46) was probably never a verb at all in this language. Consequently, if we are to provide a consistent analysis for such sentences as (44) to (46), the relevant syntactic category should be broadened to (transitive) adjuncts, of which (transitive) verbs are just a subset.

[m] Combination of several verbs, one of which is transitive

Finally, the algebraic formulas we have been listing can generally combine together (see [f]). This is basically done, one could argue, by bracketing pairs of verbs, proceeding from left to right - i.e. starting from the head. For example, when we find a string of three or four verb radicals $V_{1}-V_{2}-V_{3^{-}}$ $\mathrm{V}_{4}$, it is possible to calculate the overall valency of the resulting macro-verb by considering that the rightmost adjunct has been added to a (smaller) macro-verb, having itself its own argument structure:

$$
\left\{\left[\left(\mathrm{V}_{1}-\mathrm{V}_{2}\right)-\mathrm{V}_{3}\right]-\mathrm{V}_{4}\right\}
$$

For instance, a famous love song in Mwotlap has the following string of head + adjuncts:
$\langle$ Lak tèy yoyon̄ $\overline{\boldsymbol{e}} w \bar{e}\rangle$ no. AO:dance hold quiet good 1SG 'Just dance with me calmly.' 
Knowing the proper valency of each constituent verb, it is easy to see that their combination regularly follows the rules for each pair of verbs:

- rule $[1] \quad x$-dance + x-hold-y

$\rightarrow \boldsymbol{x}$-[dance with]-y

- rule [h] $x$-[dance with]-y $+=$ quiet

$\rightarrow x$-[dance calmly with]-y

- rule [h] $x$-[dance calmly with]- $y+=$ good

$\rightarrow x$-[just dance calmly with]-y

The result of this combination of rules, as expected, is a transitive macro-verb, whose subject is the subject of the head (by essential property of head), and whose object is the object of the only transitive verb of the string, namely $\mathrm{V}_{2}$ 'hold'.

A similar combination involves the rare pattern [k] above, in which three semantic arguments had to share only two syntactic slots. Once again, the rejected element is $y$ (the object of $V_{1}$ ), which only appears as a sentence-initial topic:

Yebek en, kemem $\langle\overline{\boldsymbol{o l}}$ tog-yoñ magaysēn $\rangle$ ige susu.
devil ANA 1Ex:PL AO:call stay-quiet sad $\quad$ PL children
[lit. That Yebek (legendary monster), we call silent sad the kids.]
'That Yebek, we call (him) to scare the kids silent.'

This sentence can be read as a development of (37) above: instead of the all-purpose verb $a k$ 'make', a more specific verb is used to express the action which is performed to achieve the goal tog-yon '(the children) be quiet'. But contrary to ordinary causative sentences [e.g. (13)], the object of $\mathrm{V}_{1}$ is here different from the global undergoer (the "causee"): parents are naming the monster in order to calm the children down. In other words:

- rule [k] $x$-call-y $+z$-be.quiet $\rightarrow x$-[shut up]-z

Now, notice the third predicate in the same series. Evidently, once a complex transitive verb has been construed, it is possible to add an extra verb $\mathrm{V}_{3}$, and thus build a new transitive macro-verb, according to rule [j] above:

- rule [j] $x$-[shut up]-z $+z$-sad $\rightarrow x$-[terrorize]-z

The reader will appreciate how much concision is made possible by the use of a serial strategy: this is how a single VP can combine such unrelated notions as 'call a name', 'be silent', and 'be sad'. The sentence itself illus- 
trates a common case of adult cruelty towards their children... but this is another issue.

\subsection{Both verbs are transitive}

We shall now mention the last combination patterns, those which involve two transitive verbs.

[n] $x-\mathrm{V}_{1}-y+x-\mathrm{V}_{2}-y \rightarrow x$-[VP]-y

No conflict arises if both verbs share the same subject and the same object: the result is a similar macro-verb. The function of $V_{2}$ is obviously not a syntactic one - e.g. valency-increasing- but consists in adding some semantic features to $\mathrm{V}_{1}$.

(49) Kèy $\langle e t-$ et vēglal te $\rangle$ no.

3PL $\mathrm{NEG}_{1}$ - see know $\mathrm{NEG}_{2}$ 1SG

'They did not recognize me.'

(50) Nok 〈tivig veteg bah〉 kē en.

1SG bury (leave) PRIOR 3SG ANA

'Let me first bury (and leave) him.'

[0] $x-\mathrm{V}_{1}-y+x-\mathrm{V}_{2}-z \rightarrow x-[\mathrm{VP}]-z$

The last case we will be facing does involve a typical conflict between arguments, in a way similar to pattern [k] above. Each transitive verb has its own object, which results in two items applying for the single object-slot of the macro-verb. Once again, the usual strategy used by Mwotlap is to select the object of $\mathrm{V}_{2}(\mathrm{z})$ to that position, thus leaving implicit the object of $\mathrm{V}_{1}(y)$.

In (51) below, 'beer' is the semantic object of $V_{1}$ 'drink'. But because $\mathrm{V}_{2}$ 'accompany' also has its own object ( $\mathrm{z}=$ 'kava'), the word 'beer' is formally excluded from the clause, and can only be retrieved from the immediately preceding context: 

(51) Nèk ta-kalēe vēh mi ni-bia... a so 〈in biyin̄ 2SG POT ${ }_{1}$-chock $\mathrm{POT}_{2}$ with ART-beer that is drink accompany $\bar{e} w \bar{e}\rangle$ na-ga. just ART-kava '[when drinking kava] one may "force it down" with beer: that means nothing but $\langle$ drink together with $\rangle$ kava.'

Such a syntactic constraint, which makes it necessary for the speaker to introduce an item (here $y=$ 'beer') in a preceding sentence, shows that Mwotlap Nuclear-layer SVCs must be analysed in a very different way from Core-layer SVCs, even in closely-related languages. For example, Paamese has the possibility, thanks to its Core-layer SVCs, to express each verb with its own object, in a structure which Crowley (1987) labels 'multiple-object serialization'. Obviously it does not have the same consequences for syntax and discourse strategies. Compare Mwotlap (51) with this Paamese sentence (1987: 39):

\section{PAA Inau na-mun sin dal oai. \\ 1SG 1SG:REAL-drink gin 3SG:REAL:accompany water}

'I drank gin with water.' [lit. I drank gin it accompanied water]

We do not think the "rules" we are defining for Mwotlap have to be conceived in terms of a purely formal constraint, e.g. Mwotlap forbidding (vs Paamese allowing) the insertion of an object inside SVCs. It seems more convincing to consider that these two languages, despite their vicinity, employ two drastically different structures, including in semantic terms. In Paamese, the verb mun 'drink' remains perfectly oriented towards its own, expected object, without being much affected by the presence or absence of a serial structure - in a way typical of Core-layer svCs. Conversely, Mwotlap svCs do considerably affect the diathetic orientation of its verbs, in such a way that in 'drink' in (51) could be said to be no longer oriented towards its "semantic object" ('beer'), but rather has become part of a macro-verb, the only function of which is to specify it semantically. Considering in biyin as a whole, we must admit that the serializing operation has blurred the syntactic link between 'drink' and 'beer', in such a way that the macro-verb 〈drink-accompany〉 is now semantically oriented towards the 'kava': it describes a certain action that the actor performs in relation with kava, e.g. increasing its effect, improving its taste, etc. In the framework of this new action, the item 'beer' is neither an object nor -we claima patient, but has now a sort of semi-presence, in the same way as a peripheral argument (instrument, locative...) could have. 


\section{2}

\section{Alexandre François}

The hypothesis we are suggesting, and which has theoretical consequences, is that when an SVC pattern has the effect of demoting an object from its position, then this demotion does not only take place at a syntactic ('surface-structure') level, which would leave intact its semantic role as a patient. In Mwotlap SVCs, any change altering the syntactic status of an object also makes it necessary to modify its semantic properties, in such a way that what was once a patient is redefined as a peripheral case role (e.g. instrument). Thus compare this sentence, in which na-hat is object and patient:

(52) a. 〈Hey $\rangle$ na-hat anen. AO:wear ART-hat that

'Put that hat on.'

....with the following one, in which the same action (hey 'put on, wear') has been integrated as the first element of a macro-verb hey goy, and has therefore lost its object:

b. $\langle$ Hey goy $\rangle$ ni-qti MI na-hat anen. AO:wear (cover) ART-head:2SG with ART-hat that

'Cover your head with that hat.'

Since it has been rejected from the position of object of $V_{1}$, the item 'hat' is no longer a patient, but has been redefined as an instrument (preposition $\mathrm{mi}$ ) within a new action: lit. 'You 〈wear-(something)-on〉 your head with that hat' ${ }^{16}$. Such sentences illustrate how Mwotlap SVCs can involve a complete reorganization of argument structure and semantic roles in the clause ${ }^{17}$.

\section{[p] Combination of several verbs, two of which are transitive}

Finally, the reader will not be surprised to learn that our corpus shows examples of serial chains with more than one transitive verb.

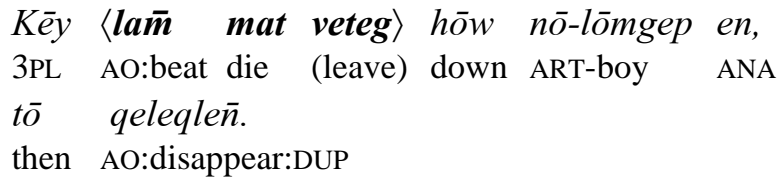

'They got rid of the boy by beating him to death, and escaped.'

This example apparently brings about a new, complex formula, in which the same argument ( $y=$ 'the boy') is simultaneously the object of $V_{1}$, the subject of $\mathrm{V}_{2}$, and again the object of $\mathrm{V}_{3}$. But as usual, we find no formal clue whatsoever which would encode the internal structure of the macro- 
verb. How can the hearer cope with such complexity, and consistently assign the right semantic role to the right argument?

As was stated in [m], this kind of multi-verbal combinations can in fact always be analysed as the result of several binary expansions, starting from the head. It is then easy to retrieve the patterns we established earlier in this study:

- rule [j] $x$-beat-y $+y$-die $\quad \rightarrow x$-[kill]-y

- rule [n] $x$-[kill]-y $+x$-leave- $y \rightarrow x$-[get rid of]-y

\subsection{Summary: Few rules, strict rules}

The function of Mwotlap macro-verbs is to define a meaningful representation of a single action, performed by a given subject at a particular point in time, exactly the same way as a simple verb would do. This is why, far from linking together any two predicates the same way as would do coordination, Mwotlap serial strategies obey strict rules regarding the semantic compatibility between its components, as well as their syntactic organization. We have shown it was possible to reduce the high diversity of all SVC instances to a finite number of thirteen regular patterns, each one being easily formalized. These patterns all consist in observing how the argument structure of a verb $V_{1}$ and a verb $V_{2}$ regularly combine, in order -for the linguist as well as the speaker- to calculate what the argument structure of the resulting 'macro-verb' will be.

All these rules ${ }^{18}$ are summarized in the following chart, each one corresponding to a single square. In bold, italic letters we represent those cases which are most frequent or productive in Mwotlap discourse, the other ones being much rarer. The two rows correspond to the valency (intransitive vs transitive) of $\mathrm{V}_{1}$; each column informs on the status of $\mathrm{V}_{2}$. Notice that the use of letter $z$ is only relevant when it contrasts with $y$ (= two distinct applicants for one object slot): hence the shaded squares.

Combination of intransitive and $/$ or transitive verbs:

Effects upon the distribution of arguments

\begin{tabular}{|l|rrrrrrr|}
\cline { 2 - 8 } \multicolumn{1}{c|}{} & $x-V_{2}$ & $\varnothing-V_{2}$ & $=V_{2}$ & $y-V_{2}$ & $x-V_{2}-y$ & $z-V_{2}$ & $x-V_{2}-z$ \\
\hline$x-V_{1}$ & $\boldsymbol{x}$-[VP] & $\mathrm{x}-[\mathrm{VP}]$ & $\boldsymbol{x}$-[VP] & $\mathrm{x}-[\mathrm{VP}]-\mathrm{y}$ & $\boldsymbol{x}$-[VP]-y & & \\
$x-V_{1}-y$ & $\mathrm{x}-[\mathrm{VP}]-\mathrm{y}$ & $\mathrm{x}-[\mathrm{VP}]-\mathrm{y}$ & $\boldsymbol{x}$-[VP]- $\boldsymbol{y}$ & $\boldsymbol{x}$-[VP]-y & $\mathrm{x}-[\mathrm{VP}]-\mathrm{y}$ & $\mathrm{x}-[\mathrm{VP}]-\mathrm{z}$ & $\mathrm{x}-[\mathrm{VP}]-\mathrm{z}$ \\
\hline
\end{tabular}




\section{Alexandre François}

While detailed discussions have already been given throughout the preceding pages, we will only add a few general comments to this chart. The combination of two verbs in Mwotlap follow a small number of very regular principles, some of which are obvious, while others are less so:

- The number of arguments of the macro-verb is never higher than two.

- The number of arguments of the macro-verb is never lower than the sum of distinct arguments associated with the input verbs.

- The subject of the macro-verb is systematically the same as for $\mathrm{V}_{1}$ (i.e. $x$ ).

- The object of the macro-verb is any argument other than $x$, associated to the input verbs (i.e. $y$ or $z$ ).

- In case of conflict for the object position, any argument introduced by $V_{2}$ (i.e. $z$, either its semantic subject or object) will have priority over the object of $\mathrm{V}_{1}$.

- In other words, the macro-verb adopts the primary orientation ${ }^{19}$ of $\mathrm{V}_{1}$; its secondary orientation depends mainly on $\mathrm{V}_{2}$.

These rules are most probably operated by the speaker, while creating new combinations and building his discourse - but also by the hearer, while endeavouring to associate the right referents with the right syntactic slots.

The high number of attested patterns does not mean that any combination of two verbs will be possible in Mwotlap. First, as we said already, the inventory of the adjunct $\mathrm{V}_{2}$ is limited, even for the patterns which are regular (e.g. no example of SVC with $\mathrm{V}_{2}=$ 'take', 'see', 'say', etc.). Secondly, one can observe that several "potential" combinations are impossible in Mwotlap: * $\left\{x-\mathrm{V}_{1}+y-\mathrm{V}_{2}-x\right\} ; *\left\{x-\mathrm{V}_{1}+y-\mathrm{V}_{2}-\mathrm{z}\right\} ; *\left\{x-\mathrm{V}_{1}-y+z-\mathrm{V}_{2}-y\right\}$; $*\left\{x-\mathrm{V}_{1}-y+y-\mathrm{V}_{2}-\mathrm{z}\right\}$. The last one, in particular, is worthy of notice, since it would have corresponded to a plausible scenario of $\mathrm{X}$ acting upon $\mathrm{Y}$, in order for this $\mathrm{Y}$ to act upon $\mathrm{Z}$; this corresponds to an "agentive causative"

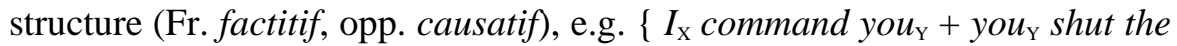
door $_{\mathrm{z}} \rightarrow *^{*}$ I command-shut... $\}$. This pattern, which is perfectly possible with Core-layer SVCs ${ }^{20}$, is impossible with the serial structures of Mwotlap: subordination structures will be used instead.

In brief, serialization strategies are not so free and random as one could believe at first sight: not only is the position of adjunct restricted to a finite inventory of verbs, but also the combinations themselves are governed by strict principles. A noteworthy paradox is that, whilst all these constraints and limitations tend to restrain haphazard innovations, they also provide efficient tools to invent novel macro-verbs, with a lesser chance of ambi- 
guity, and a higher guarantee that the communication process will be successful.

\section{Co-lexicalization and categorial change}

\subsection{Synchronic heterogeneity and language dynamics}

The last section of this paper will be concerned with diachronic change and the language dynamics implied by the serial patterns of Mwotlap. Indeed, one would get too simplistic an idea of these structures if they were to be described as a homogeneous, entirely productive set of transformative rules, applying to any lexical unit in synchrony; and conversely, it would also be erroneous to point to the other extreme, as if every 'macro-verb' were already lexicalized and learnt as such by the speakers.

After observing the way these SVCs work in Mwotlap, it seems much more accurate to synthesize these two possible interpretations. Serial verbs in Mwotlap are better defined as a heterogeneous linguistic device, involving several layers in the lexicon, and different depths in time:

- Many combinations are "already lexicalized" from the speaker's point of view, in such a way that the behaviour of the bundle cannot be unambiguously derived from the meaning of its components. These combinations are learnt as they are, as would be the case for any lexeme or idiom - cf. Eng. give up.

$\rightarrow$ e.g. mat $\bar{m} \bar{o} l$ 'faint' < mat'die' + $\bar{m} \bar{o} l$ 'return'.

- A great number of combinations, despite being already there in the language, remain relatively transparent to the hearer, i.e. could be interpreted as the "free" association of a Verb (known separately) + an adjunct (whose meaning is easily reconstructible, and thus ready to be reused) - cf. Eng. climb up.

$\rightarrow$ e.g. yow tig 'jump or dive while remaining upright' $<$ yow 'jump' + tig 'stand'.

- Out of attested combinations, especially the transparent ones, the speaker draws a set of rules. These emerging principles can be syntactic, as we saw earlier, or semantic; they may be general laws governing all serial structures, or more specific rules associated with a particular subset of verbs (e.g. verbs of movement, of speech...), or even with a single lexeme. 
$\rightarrow$ e.g. The lexeme mat 'die, dead' can be used as an adjunct:

- combined with a transitive, agentive verb, it will mean that the object dies; thus the macro-verb refers to a way of killing:

e.g. nit mat /bite+die/ 'x bite to death $\mathrm{Y}$ '.

- combined with an intransitive, active verb, it will mean that the subject metaphorically kills himself in doing an action, i.e. performs it in an intense manner (jocular use); the subject will be repeated as an object of the same verb ([b]):

e.g. lak mat /dance+die/ ' $\mathrm{x}$ dance furiously $\mathrm{x}$ '.

. combined with an intransitive, non-active verb, mat is reduplicated, and adds the meaning 'quietly'; the result is intransitive:

e.g. hag matmat /sit+die:DUP/ ' $\mathrm{x}$ sit still'.

- A certain degree of freedom is allowed within the limits of (and also thanks to) these rules. Far from damping down linguistic creativity, the high specificity of these constraints, both in syntactic and semantic terms, makes it easy for the speaker to create - and for the hearer to understand - novel Verb-Adjunct combinations.

$\rightarrow$ e.g. Regarding mat 'die, dead', any new combination $\left\langle\mathrm{V}_{1}+\right.$ mat $\rangle$

can easily be associated with one of its already attested meanings:

woh mat /hit+die/ could be created for ' $\mathrm{x}$ hit to death $\mathrm{Y}$ '

teñ mat /cry+die/ could be created for ' $\mathrm{x}$ cry hard $\mathrm{x}_{\mathrm{x}}$ '

taq matmat /stoop+die:DUP/ could be created for ' $\mathrm{x}$ stoop still'.

These novel combinations will in turn take part in the definition of slightly different rules, which will be the cause of syntactic changes and semantic shifts through time. The remainder of this paper will illustrate the two evolution paths most commonly found in Mwotlap:

- the co-lexicalization of serial verbs, close to lexical compounding;

- the emergence of productive adjuncts.

\subsection{The lexicalization of macro-verbs}

The tendency for serialized verbs to co-lexicalize, i.e. eventually behave like a single lexeme, has long been acknowledged (e.g. Crowley 1987: 61). This is a natural phenomenon, especially when one realizes that languages are more than just a list of isolate lexemes, and always involve a high number of idioms, phrases or even whole clauses as part of their resources (Pawley \& Syder 1983). Indeed, it would be clearly artificial to see all 
macro-verbs as the analysable combination, performed in situ by the speaker, of two autonomous lexemes: in the same way as show off or give up have become opaque to the speakers of English and are just memorized as a single unit, sVCs in Mwotlap also consist massively in "fixed" combinations that owe nothing to the creativity of the modern speaker.

Although this is an informal figure, we would personally estimate that in one day of linguistic interaction in Mwotlap, about 90 per cent of <VerbAdjunct> combinations are nothing but the repetition of combinations already heard by the speaker - whereas only 10 per cent(?) are novel associations which are created by applying productive rules on this matter ${ }^{21}$. Among all these 'already heard' combinations, many will eventually carry some semes which are not necessarily present or predictable from its components. A small selection of them is given below:

$$
\begin{aligned}
a k \text { 'make' + goy '(cover, obstruct...)' [see fn.17] } \\
\rightarrow \text { ak goy } \quad \text { reserve s.th. for o.s., put a taboo on s.th.; } \\
\text { reserve 〈a woman〉 as o.'s future wife, get engaged to' }
\end{aligned}
$$

(55) dēm 'think' + liwo 'big'

$\rightarrow$ dèm liwo 'consider with respect; be worried about; boast, show off'

(56) dèm 'think' + veteg 'leave'

$\rightarrow$ dēm veteg 'forget on purpose: give up, forgive; omit'

(57) tog 'live somewhere, stay for several days' + qō̄ 'be night' [see 21]

$\rightarrow \operatorname{tog} q \bar{o} \bar{n} \quad$ 'go for a picnic, spend the afternoon somewhere'

$$
\begin{aligned}
& \text { tot 'chop' + gal 'lie, tell lies' } \\
& \rightarrow \text { tot gal } \quad \text { 'notch wood; sculpt, carve an image; portray, } \\
& \text { take a photo or video of'. }
\end{aligned}
$$

Obviously, such semantic shifts make it necessary to consider these socalled "serial verbs" as single lexemes (written in one word?), and thus treat them as separate entries in a dictionary of Mwotlap (in preparation).

The question arises whether serial verbs in Mwotlap, or more generally 〈Verb-Adjunct〉 combinations, should be considered as a kind of verb compounding. We do not exclude this interpretation, considering it at least to be better - as far as Mwotlap is concerned - than the purely serializing interpretation [see fn.3]. Nevertheless, three reasons refrain us from speaking of lexical compounding:

1) A phonological criterion: Whatever their semantic evolution, Verb and Adjunct are always treated as two distinct phonological words, as is 
shown by the syllabic template mapping on each element separately ${ }^{22}$. Compare ni- 'prefix 3SG' + v(e)teg 'leave' $\rightarrow$ ni-pteg ('he leaves'); but $h \bar{o}$ 'paddle' $+v\left(\right.$ e)teg 'leave' $\rightarrow$ ho veteg $\left({ }^{*} h \bar{o}-p t e g\right)$ 'paddle away from, quit'.23

2) A syntactic criterion: Under certain conditions, it happens that some other adjunct may insert between the two elements of a "compound".

3) A semantic criterion: As the reader will have noticed throughout this paper, it is often difficult to draw the line between those cases in which it is 'clear' that $\langle$ Verb + Adjunct $\rangle$ form a single lexical unit, and those cases in which it is 'clear' that it consists of two autonomous notions.

In order to describe the facts of Mwotlap, it is not necessary to follow the old-fashioned definition of the 'lexeme' as coinciding with a single word; what we have here are whole phrases $\langle$ Verb + Adjunct $\rangle$ which are more or less (co-)lexicalized as a fixed formula.

\subsection{Intransitive $v s$ transitive adjuncts}

The second diachronic path which is often followed by Mwotlap SVCs, is for the second verb $V_{2}$ either to undergo a radical semantic shift as opposed to its use as a verbal head, or sometimes completely lose the latter, and specialize as a pure adjunct.

\subsubsection{Semantic split Verb / Adjunct}

A good example of a semantic shift affecting a serialized verb, is provided by the verb têy: as a main verb, it normally means 'hold, have in o.'s hands'. Used as an adjunct with a movement verb $\mathrm{V}_{1}$, tey y will help express such meanings as 'bring, take away (s.th. somewhere)'. The basic meaning 'hold' is maintained in these examples [see (44)], but widens to cover any value of $X$ moves with $Y$, including 'accompany (s.o. somewhere)':

(59) Hiqiyig $\langle n i-\boldsymbol{h} \overline{\boldsymbol{o}} \boldsymbol{t} \overline{\boldsymbol{e}} \boldsymbol{y}\rangle$ tita! someone AO-paddle hold Mum 'Someone takes Mum in their canoe!'

This combination is not restricted to movement verbs; with other verbs too, têy takes a general comitative meaning: 
(60) No 〈ta-lak tēy qiyig $\rangle$ na-savat.

1SG FUT-dance hold IMM ART-shoes

'I will dance with my shoes on.' (= on my feet, not *in my hands)

Finally, the same verb têy sometimes encodes a more abstract relation $f(x, y)$, with no trace of the original, lexical meaning 'hold in o.'s hands':

\begin{tabular}{|c|c|c|c|c|c|c|}
\hline$K \bar{e} y$ & $\langle n e-\boldsymbol{m} \boldsymbol{l} \overline{\boldsymbol{e}}\rangle$. & $\rightarrow$ & $K \bar{e} y$ & $\langle n e-\boldsymbol{m l e} \overline{\boldsymbol{e}}$ & $t \bar{e} y\rangle$ & па-тwитwи \\
\hline 3PL & $\begin{array}{l}\text { namuy. } \\
\text { STA-slow } \\
\text { their }\end{array}$ & & 3PL & STA-slow & hold & ART-work \\
\hline
\end{tabular}

The kind of 'semantic bleaching' involved here suggests the possibility of a shift from a lexical, semantically specific use of têy (x holds y in x's hands), to a 'grammatical use' as a "transitivizer morpheme” (by performing an action $\mathrm{V}_{1}, x$ affects $y$ in some manner) ${ }^{24}$.

\subsubsection{Emergence of pure adjuncts}

Ultimately, the two uses (as a verb $\neq$ as an adjunct) of the same lexeme will be felt to belong to two distinct linguistic units; and the decay which may affect, say, the verb will not affect the homophonous adjunct. As a consequence, the lexeme eventually leaves the category of verbs, and resembles the 'pure adjuncts' already existing in the language [cf. tiwag in ex. (4)]. The same evolutionary path was described for Paamese nuclearlayer SVCs, by Crowley (1982: 167):

The meanings of these forms as verb phrase heads and as adjuncts diverged so widely that they were no longer felt to represent the same morpheme. Subsequently, the normal processes of lexical loss and replacement resulted in the situation where some of these forms as verb phrase heads ceased to exist.

From the syntactic point of view, new adjuncts proceed either from an intransitive or from a transitive (ex-)verb. In the first case, the result will be the same as those dozens of adjuncts which have a purely semantic function, and no effect on valency. Although they do not behave as verbs in synchrony, it would be perfectly plausible that former verbs are the source of modern adjuncts like qèt '[do s.th.] completely', vatag 'already', ége 'hastily', tềqēl '[go] down', woy '[split] lengthwise'... ${ }^{25}$ In other cases, however, an intransitive adjunct may originate in a word class other than 
verbs, e.g. $\bar{e} w \bar{e}$ 'just' < adjective 'good' [ex. (47)]; or $l \bar{o}$ 'out' < POc *lua, apparently an adjunct since early stages of Oceanic.

In the second case, a transitive verb has become what may be named a "transitive adjunct". Contrary to the latter, these adjuncts have the power to alter the argument structure of a verb $\mathrm{V}_{1}$, either by increasing its valency if $\mathrm{V}_{1}$ is intransitive, or by modifying its secondary orientation if it is already transitive (following the same rules as in the table p. 133). For example, the adjuncts sas '(find)' and day '(await)', although they are not verbs in synchrony, not only change the meaning of the preceding verb, but also transitivize it:

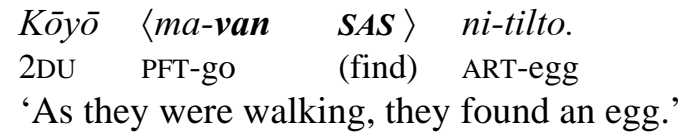

$\begin{array}{llll}\text { Nok } & \langle\text { tigtig } & \boldsymbol{D A Y}\rangle & n \bar{e} \text {. } \\ \text { 1SG AO:stand:DUP } & \text { (await) } & \text { 2SG } \\ \text { 'I was (standing) waiting for you!' }\end{array}$

Sometimes, a lexeme is already totally specialized as a transitive adjunct in younger people's speech - but suddenly some archaic or literary phrase uses it as a VP-head, betraying its true origin. This is the case with yak, which is employed as an adjunct '[take, go...] away' in about ninety-nine per cent of its uses, but appears as a verb 'pick up' in a ritual phrase connected with marriage (yak ne-sém '[the bride's father] picks up the money [given by the groom]').

Similarly, the word $v(e)$ teg which we have been glossing 'leave' is very seldom used as a verb; most of the time it forms a transitive adjunct, expressing a physical or abstract separation between the subject and the object [ex. (45)-(50)-(53)-(57)]. This includes the coding of comparison, a metaphorical extension of the idea of separation:

$\begin{array}{llll}K \bar{e} & \langle n \bar{e}-\text { mnay } & \text { VETEG }\rangle & n \bar{e} k . \\ 3 \mathrm{sG} \text { STA-clever } & \text { (leave) } & 2 \mathrm{SG} \\ \text { 'He is cleverer than you.' } & \end{array}$

As is shown in this last example, the so-called "transitivizing" function of some adjuncts does not necessarily affect verbs as such, but also adjectives or other categories; it would be better defined in terms of logical relations (Lemaréchal 1998), as a device allowing combining a first unary predicate -here the adjective $f(x)=$ 'clever' - to a binary, relational predicate $f(x, y)=$ 'be superior to'. This is how the comparative structure, par 
excellence relational, happens to be coded by a "transitive adjunct", originally a verb.

These transitive ex-verbs look as if they had transformed, one may argue, into prepositions: but what is true for other languages does not fit the structures of Mwotlap, where the strong VP-final boundary preserved $V_{2}$ from becoming a preposition ${ }^{26}$. One could then think of another possible category, i.e. grammaticalizing into an applicative morpheme ${ }^{27}$; however, contrary to applicatives, we have already seen that these adjuncts are capable of modifying the diathetic orientation of the verb $\mathrm{V}_{1}$, in such a way that the direct complement of the macro-verb eventually takes over the semantic role of patient.

Consequently, the new 'grammatical unit' arising from the diachronic specialization of transitive verbs in the adjunct-position, should no longer be described as a verb any more (contra Crowley 1987: 61), nor as a preposition or an applicative. Rather, the most reasonable analysis would certainly consist in sticking to the "vernacular" category of (intransitive vs transitive) adjunct, to which are associated certain syntactic and semantic properties, different from other word classes. Although this approach seems to partially hamper cross-linguistic comparison, it has the paramount advantage of allowing a deeper understanding of the synchronic structures, as well as the historical evolution, of Mwotlap grammar. Thanks to this methodological caution, it becomes obvious why some nouns, some adjectives, some verbs (etc.) seem to be merging into a single category, obeying the same rules, whenever they follow the head of a VP. This is the only way a vernacular-oriented analysis of the language becomes feasible, as a necessary requirement before any cross-linguistic statement is made.

\section{Conclusion: Serial verbs or Adjuncts?}

Although, at first sight, Mwotlap is a good example of what we expect a "serializing language" to be, the present paper showed several reasons why such a tag would mislead linguistic analysis rather than help it. The case where a verbal head $V_{1}$ is indeed followed by one or more verb roots, rather than being interpreted as a serial verb construction, appears to be merely a subcase of a more general and productive pattern in this language, i.e. the syntactic function of adjunct. As far as these adjuncts are concerned, the only grammatical boundary that really matters is not so much the 


\section{2}

Alexandre François

distinction between parts of speech (adjectives, verbs...), but the contrast between unary and binary predicates:

Unary $v s$ binary predicates in the adjunct position

\begin{tabular}{lll}
\hline Type of predicate & Argument slots & \multicolumn{1}{c}{ Syntactic categories } \\
\hline Unary predicate & 1 slot: $\mathrm{f}(\mathrm{x})$ & $\begin{array}{l}\text { adjectives }+ \text { nouns }+ \text { intransitive } \\
\text { verbs }+ \text { intransitive pure-adjuncts } \\
\text { transitive verbs } \\
\text { Binary predicate }\end{array}$ \\
\hline
\end{tabular}

While unary predicates have little effect upon the argument structure of the macro-verb, binary adjuncts do influence its syntactic behaviour, following complex rules which were detailed here. The fact that some verbs, along with other word classes, are taking part in this mechanism, is indeed worth of notice; but the quest for data on "serial verbs" as such should not obscure the main pivot of the system, which is not so much the verb as a lexical category, but rather the adjunct as a syntactic function in the clause.

\section{Orthographic conventions and abbreviations.}

The spelling conventions adopted for Mwotlap include the following:

$$
\bar{e}=[\mathrm{I}] ; \bar{o}=[\mathrm{U}] ; g=[\gamma] ; b=\left[{ }^{\mathrm{m}} \mathrm{b}\right] ; d=\left[{ }^{\mathrm{n}} \mathrm{d}\right] ; q=\left[{ }^{\mathrm{k}} \mathrm{p}^{\mathrm{w}}\right] ; \bar{m}=\left[{ }^{\mathrm{n}} \mathrm{m}^{\mathrm{w}}\right] ; \bar{n}=[\mathrm{y}] \text {. }
$$

The abbreviations used in literal translations include:

$\begin{array}{llll}\text { ANA } & \text { anaphoric marker } & \text { PRD } & \text { predicative } \\ \text { AO } & \text { Aorist } & \text { PRET } & \text { Preterite } \\ \text { ART } & \text { article } & \text { PRIOR } & \text { Prioritive } \\ \text { DU } & \text { dual } & \text { PROH } & \text { Prohibitive } \\ \text { DUP } & \text { reduplicated form } & \text { PRSP } & \text { Prospective } \\ \text { IMM } & \text { Immediate future } & \text { STA } & \text { Stative } \\ \text { NEG } & \text { negation } & \text { 1EX } & \text { first exclusive } \\ \text { PFT } & \text { Perfect } & \text { 1IN } & \text { first inclusive } \\ \text { POT } & \text { Potential } & & \end{array}$




\section{Notes}

1. In this regard, Mwotlap contradicts the tendency proposed by Foley and Olson (1985) that an SVO language should make use of Core juncture rather than Nuclear juncture. Other svo languages, like Paamese (Crowley 1987:82) and Lewo (Early 1993:88), have also been mentioned in this respect.

2. This description of $\mathrm{V}_{2}$ as being essentially a "modifier" to $\mathrm{V}_{1}$ should be taken for what it is: a first attempt to describe Mwotlap serial verbs in broad, nontechnical terms. The following pages will show that the function of $V_{2}$ is obviously more complex, and cannot be reduced to a role of lexical specification (see for example the case of causative serialization). The relevant point at this stage of our presentation is to underline the syntactic asymmetry between $\mathrm{V}_{1}$ (the head) and $\mathrm{V}_{2}$ (the adjunct).

3. By preferring the 'adjunct' interpretation rather than the 'serializing' one, we support - at least for Mwotlap - the analysis of Early (1993: 80-81) and even Crowley (1982:166), contra Crowley (1987:59).

4. Foley (1986: 117), from Olson (1981). See also the Kalam examples cited by Senft (this volume), after Pawley (1993: 95).

5. A sentence like this one clearly refers to several distinct actions ('kill, cut up, eat'...). Saying this does not contradict the hypothesis, often formulated (Givón 1991a; Durie 1997: 291), that globally only one event is involved.

6. The clear presence of these pauses, as well as coordinators, makes it impossible to talk about Core-layer serialization. The only case which shows Corelayer SVC is reserved to purpose clauses in an Irrealis context, e.g. following a general statement, a prospective clause or an order (Aorist): Lep me ne-bē nok in. 'Give me some water [so that] I drink' (François 2003: 187). Even though the absence of pause between both clauses strongly recalls Core-layer serialization, it must be noted that this structure is functionally very limited.

7. Likewise, Ross (1998:35) chooses to talk about "adjectival verbs" rather than “adjectives” for Proto Oceanic. François (2001) discusses in detail the issue of Mwotlap parts of speech, including the adjective vs verb contrast.

8. A similar phenomenon occurs in English: compare You hit him to death (with transitive hit), and You danced yourself to death (with intransitive dance).

9. This corresponds to what Crowley (1987: 40, 49) labelled 'ambient serialization' (e.g. /I hit you it was hard/ = 'I hit you hard'); but his description of $\mathrm{V}_{2}$ as a "general” predication, in our opinion, somewhat lacks precision.

10. The corresponding statements make use of an "impersonal" subject mahe ('place') for this kind of weather sentence: Mahe $m \bar{o}-q \bar{o} \bar{n}$ 'It is night' [lit. The place is night]. That mahe is an empty argument, not a true one, is proven 
precisely by the impossibility of finding it as an object of a $\left\langle\mathrm{V}_{1}-\mathrm{V}_{2}\right\rangle$ bundle: thus $\S[\mathrm{d}] \neq \S[\mathrm{e}]$.

11. Further evidence against this general prediction will appear in $\S[\mathrm{k}]$.

12. The verb S.P.R. is a loanword from pidgin bislama S.P.R. [Espiar], which stands for Sperem Pablik Rot, lit. 'hit the public road', i.e. 'roam, wander aimlessly all day long'. This has become a full verb in Mwotlap, including the possibility of root reduplication, hence S-S.P.R. [EsEspiar].

13. Mwotlap has lost the POc causative prefix *pa(ka)-, except for two residual, unanalysable, verbal lexemes wot 'be born' > vawot 'give birth to'; êh 'live' > vaēh 'save s.o.'s life, rescue, cure'.

14. For other "potential" formulas, the risk of semantic ambiguity of a serialized VP would be so high that subordination is always the rule: see the case of $\left\{x-\mathrm{V}_{1}-y+y-\mathrm{V}_{2}-z\right\}$ p.134.

15. The notion of relational seme appears to be particularly fertile in the theory developed by Alain Lemaréchal, regarding the semantic and syntactic mechanisms of verb serialization (1998: 206-233).

16. Very similar sentences are reported for neighbouring Mota: saru GORO natarapē̄a mun o siopa 'clothe over your body with a garment' (Codrington 1885: 293).

17. The last example, along with many others, is commented in detail in a paper (François $2000 \mathrm{~b}$ ) dedicated to the numerous valency-effects of this adjunct (not verb) goy $[V+$ goy = 'cover, obstruct, occupy, forbid, react, disturb, dominate, reserve, fetch, protect, assist...' (< POc *koro 'to surround; fortified village')] and to its interest for syntactic and semantic theory.

18. All, except [b] - which is exceptional anyway - plus the cases of combinations involving more than two verbs ([f], [m], [p]); we showed that these could always be analysed into smaller, binary combinations.

19. The notion of diathetic orientation of the verb, "primary orientation" towards the subject and "secondary orientation" towards the object, is developed by Lemaréchal (1989).

20. For example, see François (2002: 112 99) for Araki: Nam vadai-a ni-a co les moli '(lit.) I told him (that) he should see the chief'.

21. This kind of approximation would be very difficult to check. Among other things, this issue will also depend on the speaker's personality; the more easily one breaks new ground in forging SVCs, the better reputation he will get as a language connoisseur.

22. This point is more detailed in François (to appear); for similar remarks about Paamese, see Crowley (1987: 60).

23. In the terminology proposed by Durie (1997: 302-303), Mwotlap SVCs would thus be defined as [+ contiguous] because $V_{2}$ immediately follows $V_{1}$, but 
[- incorporating], since the two verb roots remain as two distinct phonological words.

24. Although the verb 'take' (Mtp lep) must be distinguished from 'hold' (tēy), the situation here described strongly recalls the evolution of Mandarin ba into an Object marker (Li and Thompson 1974c); closer to us, see the New Caledonian languages described by F. Ozanne-Rivierre (this volume).

25. This general remark sometimes corresponds to a mere hypothesis, and sometimes is confirmed by further etymological or dialectological research. Although such forms as $q \bar{e} t$, têqqèl, day are only used as pure adjuncts in Mwotlap, their cognate forms in Mwesen (Vanua-lava I., 8 speakers; pers. data) are still verbs: $q \bar{e} t$ 'finish', tēqeel 'go down', nar 'await'. Similarly, woy corresponds to a verb in most Vanuatu languages < (Proto NCV) *vora 'break, divide, split' (Clark 2000), etc.

26. There are a few exceptions to this "impossible evolution", since a few adjuncts have historically crossed over the VP (right) boundary. For instance, the Proto Oceanic verb *suRi [glossed 'prepositional verb: allative' by Ross (1988)] appears in Mwotlap not as a verb, but as a transitive adjunct hiy '(do $\mathrm{V}_{1}$ ) having s.th. in mind', thus still VP-internal; on the other hand, it has also grammaticalized as a preposition, outside the VP, coding for Dative.

27. An Applicative morpheme is a VP-internal marker modifying the diathesis of a verb, in such a way that what could have been coded as an oblique complement is construed directly, as if it were an object, but it does not eliminate the other object. Applicatives are a kind of 'incorporated preposition': cf. Guinea Fula En hab6-ay ledde 'we shall bind the wood' $\rightarrow$ En hab6-ir-ay ledde boggol '(lit.) we shall bind-with the wood a cord' (Labatut n.d.: 126). On Applicatives, see Palmer (1994), Lemaréchal (1998: 189). 